\title{
Hematological Parameters in Cows in Early Lactation Treated with Ketoprofen and their Relationship with Lipid Mobilization and Ketogenesis
}

\author{
Zorana Kovacevic, Dragica Stojanovic, Marko Cincovic, Branislava Belic, Ivana Davidov \& Mihajlo Erdeljan
}

\begin{abstract}
Background: Dairy cows are exposed to numerous hematological and biochemical changes, what is bringing cows into the state of increased metabolic activity and physiological adaptations. These adaptive processes have resulted in increased lipid mobilization and ketogenesis with increased concentration of non-esterified fatty acids (NEFA) and beta-hydroxybutyrate (BHB). As a non steroidal anti-inflammatory drug, ketoprofen produces anti-inflammatory effects. The main objective of the present study was to found relationship between hematological parameters and ketoprofen administration and high lipid mobilization and ketogenesis in cows treated with ketoprofen immediately after calving.

Materials, Methods \& Results: Ketoprofen was used ( $3 \mathrm{mg} / \mathrm{kg}$ body weight) intramuscularly for three consecutive days post-partum on 15 cows of Holstein-Friesian breed. Cows of the control group $(n=15)$ were not treated with ketoprofen. Blood samples were collected at the day of calving, in the first and in the second week after parturition from the coccygeal vein of the both groups. Hematological parameters (erythrocytes, hemoglobin, neutrophils, lymphocytes and mean platelet volume) were determined on the automatic hematological counter. Metabolic parameters (NEFA, BHB) were determined by standard colorimetric kits using a semi-automatic biochemistry analyzer. Student's t-test was used to determine the influence of the application of ketoprofen to the hematological parameters. The data analysis was performed using SPSS, version 19.0, software package for Microsoft Windows (IBM, Armonk, NY, USA). The results of comparison with ( $P$ $<0.05)$ were considered to represent statistically significant differences. Difference in correlation test between NEFA and BHB and other blood parameters in experimental and control group of cows were determined by the Fischer r-to-Z transformation. The research results show that there was a increased red blood cell count and a higher concentration of hemoglobin $(P<0.05)$, fewer neutrophils $(P<0.01)$, lower number of lymphocytes $(P<0.01)$ and fewer mean platelet volume in cows that received ketoprofen after calving than those of the control. Determined hematological parameters and values of NEFA and BHB are in correlation. The correlation coefficients were significantly lower in the experimental group of cows. The intensity of the connection between hematological parameters and value of NEFA and BHB decreases. Discussion: It is well known that dairy cows with excessive adiposity manifest a low-grade inflammation and that elevated NEFA concentrations present positive risk factors for many proinflammatory diseases. Analyzing the results in this examination, it has been noticed that the increase of NEFA and BHB after calving were significantly lower in group of cows treated with ketoprofen. Also, determined hematological parameters and values of NEFA and BHB are in correlation. The intensity of these connection decreases in ketoprofen treated cows. In current study, in cows treated with ketoprofen there is decrease in concentrations of inflammatory mediators such as neutrophils and lymphocytes. Red blood cell and hemoglobin concentration decreased in the peripartal period as a result of inflammation. In cows treated with ketoprofen these concentrations increased. In many inflammatory conditions mean platelets volume is increased while there is a decrease in ketoprofen treated cows. Presented results indicate strong relationship between the concentration of NEFA, as well as BHB and hematological parameters indicating that the dependence of hematological parameters of intensity of lipid mobilization and ketogenesis was significantly lower in cows treated with ketoprofen immediately after calving.
\end{abstract}

Keywords: ketoprofen, hematological parameters, lipid mobilization, ketogenesis, dairy cows. 


\section{INTRODUCTION}

The transition period spans from three weeks before to three weeks after calving [12,30] when dairy cows experience a sudden increase in energy requirements imposed by the onset of lactation and by negative energy balance (NEB) [20]. A significant adaptation to the NEB is the lipid mobilization from adipose tissue what cause increase in blood concentration of nonesterified fatty acids (NEFA) and beta-hydroxybutyrate (BHB) [17].

Increased circulating NEFA concentrations may presents positive risk factors for many inflammatory diseases in dairy cows $[5,10,25,31]$ and can impaired lymphocyte function [11,19]. Also, the link between inflammatory diseases and metabolic responses around calving may be mediated through impaired neutrophil function [6,14]. Number of eritrocytes and hemoglobin concentration are impaired [4].

The activity of the eicosanoid-producing enzymes cyclooxygenase (COX) and 15 lipoxygenase is increased during the transition period $[1,27]$. COX pathway products are related to inflammatory events and in dairy cows, the COX pathway is composed of 2 enzyme isoforms, COX-1 and COX-2 [11,7].

All NSAIDs (non steroidal anti-inflammatory drugs) produces anti-inflammatory effects by inhibiting cyclooxygenase enzymes, which leads to decreased pain and inflammation. As a NSAID, ketoprofen inhibits both izooforme COX enzyme, although it is considered as a COX-1 selective drug [8,28].

The aim of the present study was to found relationship between hematological parameters and ketoprofen administration and high lipid mobilization and ketogenesis in cows treated with ketoprofen immediately after calving.

\section{MATERIALS AND METHODS}

\section{Animals and blood collection}

Experimental group of animals included 15 Holstein-Friesian cows treated with ketoprofen immediately after calving, while control group included 15 cows and they were not treated with ketoprofen. Ketoprofen was administered in therapeutic dose, intramusculary, $3 \mathrm{mg} / \mathrm{kg}$ body weight in the period of three consecutive days after parturition, starting at the first day post partum. Blood samples of the experimental and control group of cows were collected at commercial dairy farm in Banatska Topola, Republic of Serbia. They were taken three times, after calving, in the first and in the second week after parturition. They were collected from the coccygeal vein using sterile vacuum tubes ${ }^{1}$ containing serum separation gel for hematological analyses and using sterile vacuum tubes $^{2}$ containing EDTA for biochemical analyses.

\section{Measurement of hematological and metabolic parameters}

Hematological parameters such as the total number of erythrocytes, hemoglobin concentration, number of neutrophils, lymphocytes and the mean platelet volume were determined by hematological analysis on the counter Analyser ${ }^{3}$. Metabolic parameters such as NEFA and BHB were determined by using the colorimetric reaction according to the manufacturer's instructions using Colorimetric Kits ${ }^{4}$ and were measured using a semi-automatic biochemistry Analyzer ${ }^{5}$.

\section{Statistical analyses}

Student's $t$-test was used to determine the influence of the application of ketoprofen to the hematological parameters. The data analysis was performed using SPSS, version 19.0, software package for Microsoft Windows (IBM, Armonk, NY, USA). The results of comparison with $P<0.05$ were considered to represent statistically significant differences.

Difference in correlation test between NEFA and BHB and other blood parameters in experimental and control group of cows were determined by the Fischer r-to-z transformation.

\section{RESULTS}

The research results show that there is a decreases in NEFA and BHB concentrations in cows treated with ketoprofen than those of the control group [Figures $1 \& 2$ ].

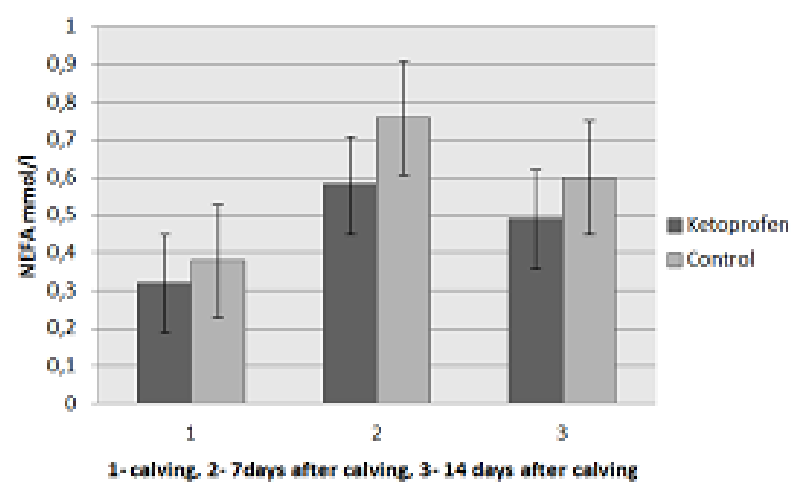

Figure 1. Effect of ketoprofen on NEFA concentration in cows in early lactation. 
Group of cows treated with ketoprofen show increases of red blood cell count in the first and in the second week after parturition [Figure 3]. Also, there is higher concentration of hemoglobin in experimental group of cows [Figure 4]. Fewer neutrophils concentration is present in cows treated with ketoprofen in the first and in the second week after parturition [Figure 5]. Also, there is decreases in number of lymphocytes in experimental group of cows in the first and in the second week after parturition [Figure 6].
There is fewer mean platelet volume in cows that received ketoprofen after calving than those of the control [Figure 7]. Determined hematological parameters and values of NEFA and BHB are in correlation. As shown in Table 1, the correlation coefficients were significantly lower in the experimental group of cows and the intensity of the connection between hematological parameters and value of NEFA and BHB decreases.

Table 1. Effect of the application of ketoprofen on correlations between parameters in cows in early lactation

\begin{tabular}{ccc}
\hline & NEFA & BHB \\
\hline \multirow{2}{*}{ Erythrocytes } & 0.37 & NS \\
& 0.35 & NS \\
\hline \multirow{2}{*}{ Hemoglobin } & NS & -0.52 \\
& NS & $-0.31^{*}$ \\
\hline \multirow{2}{*}{ Neutrophils } & 0.54 & 0.49 \\
& $0.24^{* *}$ & $0.32^{*}$ \\
\hline \multirow{2}{*}{ Limphocytes } & 0.49 & NS \\
& $0.31^{*}$ & NS \\
\hline \multirow{2}{*}{ Mean platelet volume } & 0.42 & 0.36 \\
& $0.32^{*}$ & $0.22^{*}$ \\
\hline
\end{tabular}

a-correlation in a group that did not receive ketopofen, b-correlation of the group of cows who received ketoprofenThe significance of the difference in the coefficient of correlation in cows receiving and not receiving ketorpofen for $n=45$ $* P<0.05 ; * * P<0.01$

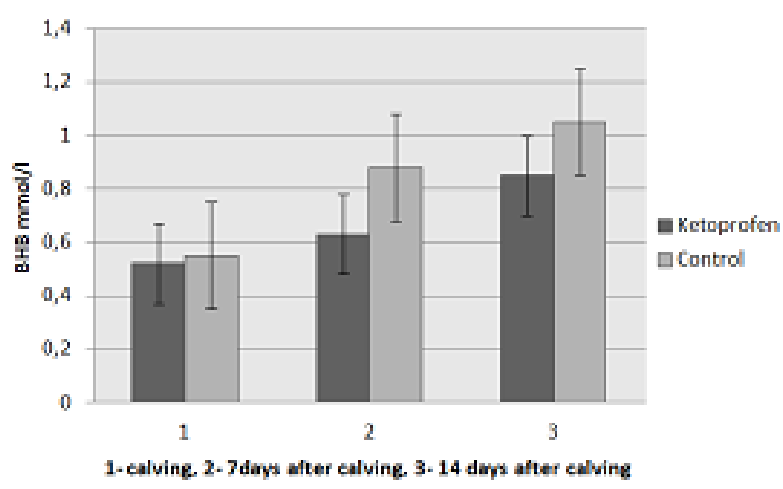

Figure 2. Effect of ketoprofen on BHB concentration in cows in early lactation.

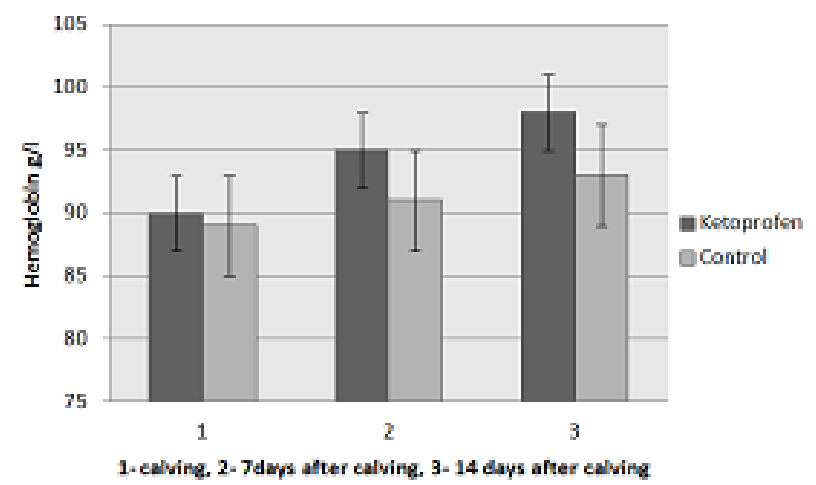

Figure 4. Effect of ketoprofen on hemoglobin concentration in cows in early lactation.

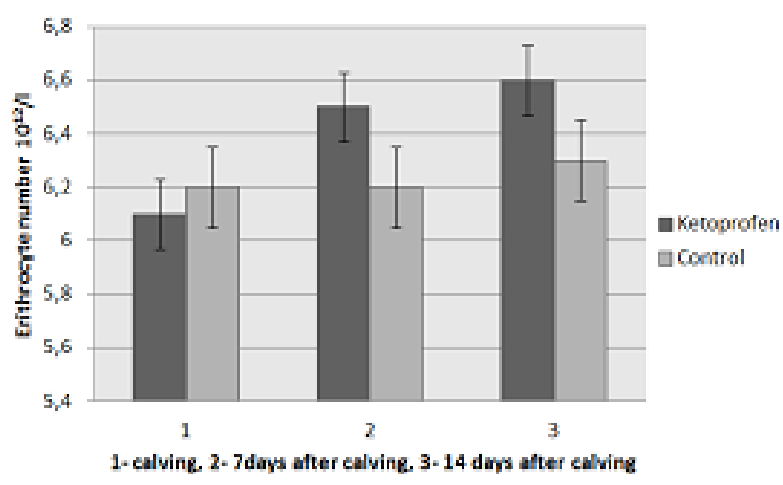

Figure 3. Effect of ketoprofen on eritrocyte concentration in cows in early lactation.

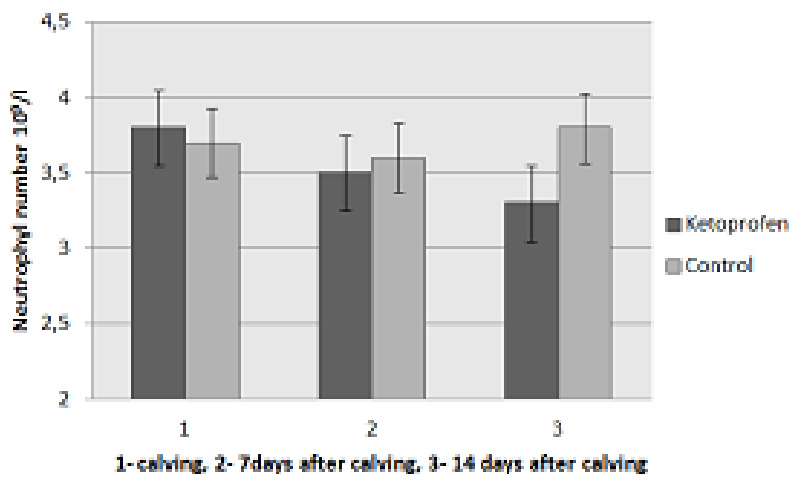

Figure 5. Effect of ketoprofen on the number of neutrophils in cows in early lactation. 


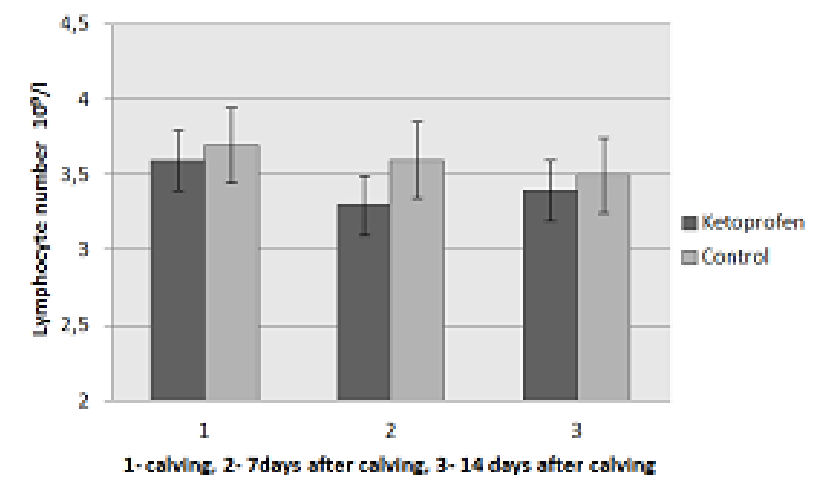

Figure 6. Effect of ketoprofen on the number of lymphocytes in cows in early lactation.

\section{DISCUSSION}

Studies in human medicine demonstrated that high concentrations of NEFA induce low-grade inflammation and affect immune function [15,21]. In dairy cows, excessive lipid mobilization from adipose tissue is linked with greater incidences of health problems [12]. It is well known that dairy cows with excessive adiposity manifest a low-grade inflammation [16].

Some researchers demonstrated that elevated NEFA concentrations present positive risk factors for many proinflammatory diseases in dairy cows $[5,10,25]$. Also, during the transition period when NEFA concentration increase, dairy cows experience immune dysfunction that enhances their susceptibility to disease $[3,11,23,25]$. This suggests that perhaps inflammation underlies metabolic disturbances in obese dairy cows.

In our current study, the increase of NEFA and BHB after calving were significantly lower in ketoprofen treated cows than those of control. These changes confirm a lower adipose tissue mobilization in cows treated with NSAIDs and are in accordance with results of other researchers [29]. Determined hematological parameters and values of NEFA and BHB are in correlation. The intensity of these connection decreases in ketoprofen treated cows.

In one study administration of the NSAID for the first 7 days of lactation showed that inflammationassociated pathways are involved in homeoretic adaptations to lactation [13]. Also, examining the effects of ketoprofen administration in dairy cows it was concluded that ketoprofen significantly improved recovery in clinical mastitis indicating that ketoprofen did suppress inflammation [12,26].

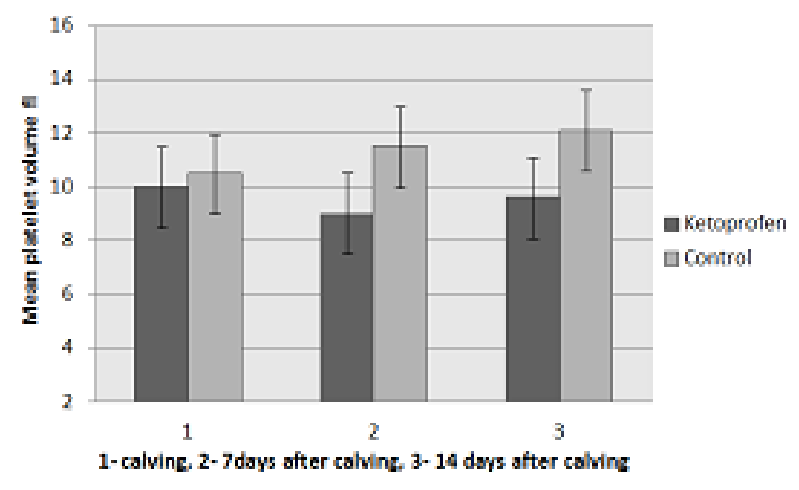

Figure 7. Effect of ketoprofen on the mean volume of platelets in cows in early lactation.

Changes in concentration of lipids in plasma associated with lipid mobilization could affect leukocyte activity and increase incidence to disease [9,11]. Cows that have excessive lipid mobilization and ketogenesis as well as reduced concentrations of glucose have a significantly higher ratio of inflammatory mediators such as neutrophils and lymphocytes what have been reported in previous studies $[3,23]$. Contrary to this findings, in current study in cows treated with ketoprofen there is decrease in concentrations of neutrophils and lymphocytes. It potentially could be linked with anti inflammatory effects of ketoprofen [2].

Concentration of red blood cell and hemoglobin in the peripartal period decrease $[3,23]$, also as a result of inflammation [24] while these concentration increases in cows treated with NSAID [29] what matches with our findings.

Platelets play a complex role in hemostasis and thrombosis and in other physiological or pathological processes including inflammation, malignancy and the immune response [22]. In many inflammatory conditions, values of mean platelets volume is increased, such as in animals affected with acute peritonitis [18]. There is a decrease in mean volume of platelets in ketoprofen treated cows and this, in part, explains the anti-inflammatory activity of ketoprofen.

\section{CONCLUSION}

In conclusion, presented results indicate strong relationship between the concentration of NEFA, as well as BHB and hematological parameters. The dependence of hematological parameters of intensity of lipid mobilization and ketogenesis was significantly lower in cows treated with ketoprofen immediately after calving. 
Z. Kovacevic, D. Stojanovic, M.R. Cincovic, et al. 2016. Hematological Parameters in Cows in Early Lactation Treated with Ketoprofen and their Relationship with Lipid Mobilization and Ketogenesis.

ActaScientiae Veterinariae. 44: 1348.

MANUFACTURERS

${ }^{1}$ Becton Dickinson and Company. Franklin Lakes, NJ, USA.

${ }^{2}$ BD Plymouth. Plymouth, UK.

${ }^{3}$ Drew Scientific Ltd. Cumbria, UK.

${ }^{4}$ Randox Laboratories Ltd. London, UK.

${ }^{5}$ Rayto Electronics Inc. Shenzhen, China.
Funding. This research was financed by the Ministry of Science and Technological Development, Republic of Serbia, Project IDP. No 31062.

Declaration of interest. The authors report no conflicts of interest. The authors alone are responsible for the content and writing of the paper.

\section{REFERENCES}

1 Aitken S.L., Karcher E.L., Rezamand P., Gandy J.C., VandeHaar M.J., Capuco A.V. \& Sordillo L.M. 2009. Evaluation of antioxidant and proinflammatory gene expression in bovine mammary tissue during the periparturient period. Journal of Dairy Science. 92: 589-598.

2 Banting A., Banting S., Heinonen K. \& Mustonen K. 2008. Efficacy of oral and parenteral ketoprofen in lactating cows with endotoxin-induced acute mastitis. Veterinary Record. 163: 506-509.

3 Belic B., Cincovic M.R., Krcmar Lj. \& Vidovic B. 2011. Reference values and frequency distribution of hematological parameters in cows during lactation and in pregnancy. Contemporary agriculture. 60: 145-51.

4 Belic B., Cincovic M.R., Stojanovic D., Kovacevic Z. \& Vidovic B. 2010. Morphology of erythrocyte and ketosis in dairy cows with different body condition. Contemporary agriculture. 59: 306-311.

5 Bernabucci U., Ronchi B., Lacetera N. \& Nardone A. 2005. Influence of Body Condition Score on Relationships Between Metabolic Status and Oxidative Stress in Periparturient Dairy Cows. Journal of Dairy Science. 88: 2017-2026.

6 Bertoni G. E., Trevisi X.H. \& Bionaz M. 2008. Effects of inflammatory conditions on liver activity in puerperium period and consequences for performance in dairy cows. Journal of Dairy Science. 91: 3300-3310.

7 Bogatcheva N.V., Sergeeva M.G., Dudek S.M. \& Verin A.D. 2005. Arachidonic acid cascade in endothelial pathobiology. Microvascular Research. 69: 107-127.

8 Brideau C., Van Staden C. \& Chan C.C. 2001. In vitro effects of cyclooxygenase inhibitors in whole blood of horses, dogs, and cats. American Journal of Veterinary Research. 62: 1755-1760.

9 Burvenich C., Bannerman D.D., Lippolis J.D., Peelman L., Nonnecke B.J., Kehrli Jr. M.E. \& Paape M.J. 2007. Cumulative physiological events influence the inflammatory response of the bovine udder to Escherichia coli infections during the transition period. Journal of Dairy Science. 90: E39-54.

10 Calder P.C. 2008. The relationship between the fatty acid composition of immune cells and their function. Prostaglandins, Leukotrienes and Essential Fatty Acids. 79: 101-108.

11 Contreras G.A., O'Boyle N.J., Herdt T.H. \& Sordillo L.M. 2010. Lipomobilization in periparturient dairy cows influences the composition of plasma nonesterified fatty acids and leukocyte phospholipid fatty acids. Journal of Dairy Science. 93: 2508-2516.

12 Drackley J.K. 1999. Biology of dairy cows during the transition period: the final frontier? Journal of Dairy Science. 82(11): 2259-2273.

13 Farney J.K., Mamedova L.K. , Coetzee J.F., KuKanich B., Sordillo L.M., Stoakes S.K., Minton J.E., Hollis L.C. \& Bradford B.J. 2013. Anti-inflammatory salicylate treatment alters the metabolic adaptations to lactation in dairy cattle. American Journal of Physiology - Regulatory, Integrative and Comparative Physiology. 305(2): 110-117.

14 Gilbert R.O., Grohn Y.T., Miller P.M. \& Hoffman D.J. 1993. Effect of parity on periparturient neutrophil function in dairy cows. Veterinary Immunology and Immunopathology. 36: 75-82.

15 Harford K.A., Reynolds C.M., McGillicuddy F.C. \& Roche H.M. 2011. Fats, inflammation and insulin resistance: insights to the role of macrophage and T-cell accumulation in adipose tissue. Proceedings of the Nutrition Society. 70: 408-417.

16 Hotamisligil G.S. 2006. Inflammation and metabolic disorders. Nature. 444: 860-867.

17 Ingvartsen K.L. \& Andersen J.B. 2000. Integration of metabolism and intake regulation: a review focusing on periparturient animals. Journal of Dairy Science. 83: 1573-1597.

18 M.A. 2011. Evaluation of Hemogram, Haptoglobine and Clotting Factors Indices in Cattle Affected with Acute and Chronic Peritonitis. Journal of Animal and Veterinary Advances. 10(1): 11-17.

19 Lacetera N., Scalia D., Franci O., Bernabucci U., Ronchi B. \& Nardone A. 2004. Effects of Nonesterified Fatty Acids on Lymphocyte Function of Dairy Heifers. Journal of Dairy Science. 87: 1012-1014. 
20 Leroy J.L.M.R., Vanholder T., Van Knegsel A.T.M., Garcia-Ispierto I. \& Bols P.E.J. 2008. Nutrient Prioritization in Dairy Cows Early Postpartum: Mismatch Between Metabolism and Fertility? Reproduction in Domestic Animals. 43: 96-103.

21 Linegaard B., Ditlevesen S., Plomgaard P., Mittendorfer B. \& Pedersen B.K. 2013. Acute reduction of lipolysis reduces adiponectin and IL-18: evidence from an intervention study with acipimox and insulin. Diabetologia. 56(9): 2034-2043.

22 McNicol A. \& Israels S.J. 2008. Beyond Hemostasis: The Role of Platelets in Inflammation, Malignancy and Infection. Cardiovascular \& Haematological Disorders-Drug Target. 8: 99-117.

23 Mirzadeh K.H., Tabatabei S., Bojarpour M. \& Mamoei M. 2010. Comparative study of hematological parameters according strain, age, sex, physiological status and season in Iranian cattle. Journal Animal Veterinary Advances. 9(16): 2123-2127.

24 Morceau F., Dicato M. \& Diederich M. 2009. Pro-Inflammatory Cytokine-Mediated Anemia: Regarding Molecular Mechanisms of Erythropoiesis. Mediators of Inflammation. Article ID 405016. [Fonte: <http://dx.doi. org/10.1155/2009/405016>].

25 Sordillo L.M., Contreras G.A. \& Aitken S.L. 2009. Metabolic factors affecting the inflammatory response of periparturient dairy cows. Animal Health Researh Reviews. 10: 53-63.

26 Shpigel N.Y., Chew R., Winkler M., Saran A., Ziv G. \& Lono F. 1994. Anti-inflammatory ketoprofen in the treatment of field cases of bovine mastitis. Research in Veterinary Science. 56: 62-68.

27 Silva E., Gaivão M., Leitão S., Amaro A., Costa L.L. \& Mateus L. 2008. Blood COX-2 and PGES gene transcription during the peripartum period of dairy cows with normal puerperium or with uterine infection. Domestic Animal Endocrinology. 35: 314-323.

28 Streppa H.K., Jones C.J. \& Budsberg S.C. 2002. Cyclooxygenase selectivity of nonsteroidal anti-inflammatory drugs in canine blood. American Journal of Veterinary Research. 63: 91-94.

29 Trevisi E., Ferrari A., Archetti I. \& Bertoni G. 2005. Anti-inflammatory treatments in calving dairy cows: effects on haematological and metabolic profiles. Italian Journal of Animal Science. 4(2): 203-205.

30 Quiroz-Rocha G.F., LeBlanc S., Duffield T., Wood D., Leslie K.E. \& Jacobs R.M. 2009. Evaluation of prepartum serum cholesterol and fatty acids concentrations as predictors of postpartum retention of the placenta in dairy cows. Journal of the American Veterinary Medical Association. 234(6): 790-793.

31 Wood L.G., Scott H.A., Garg M.L. \& Gibson P.G. 2009. Innate immune mechanisms linking non-esterified fatty acids and respiratory disease. Progress in Lipid Research. 48: 27-43. 